BLS 32, No 1 2006. DOI: http://dx.doi.org/10.3765/bls.v32i1.3478 (published by the Berkeley Linguistics Society and the Linguistic Society of America)

\title{
The Perfect Converb? Semantically-Related Functions of the Sinhala Conjunctive Participle
}

\author{
CHRIS TAYLOR \\ Rice University
}

\section{Introduction}

In recent years, the term 'converb' has increasingly been used to describe constructions with crosslinguistically comparable forms and functions which include nonfinite verbal affixation, dependency on a finite verb, clause linking, and the sequencing of events (Bickel 1998, Genetti 2005, Hasplemath and König 1995, Masica 1991). ${ }^{1}$ Among such constructions, two broad areal categories have been suggested (Bickel 1998), European and Asian converbs, differing primarily with respect to the potential for what Bickel refers to as 'narrative chaining:' Asian converbs perform a clause chaining function in addition to various types of modification, whereas the European type "does not include chaining functions but rather stands in a binary relation to the main verb." One form potentially instantiative of the former category comes from the Indo-Aryan language Sinhala, namely the conjunctive participle. Examples include the following. ${ }^{2}$
(1) booṭəle wæti-la kæụuna
bottle fall-CP break-PAST
The bottle fell and broke.
(2) miniha gallak ussə-la wandura-ț gaha-lla duwə-la heyguna man rock lift-CP monkey-DAT throw-CP run-CP hide-PAST The man picked up a rock, threw it at the monkey, ran away, and hid.

\footnotetext{
${ }^{1}$ My thanks to Nissanka Wickremasinghe, for his patience and insights, and to Michel Achard, Claire Bowern, and Robert Englebretson, for their suggestions and comments. Of course, any remaining errors or omissions are my own.

2 The following glosses will be used throughout: ACC (accusative); CONJ (conjunction); CP (conjunctive participle); COMP (complementizer); DAT (dative); GEN (genitive); INF (infinitive); INST (instrumental); PL (plural); PP (postposition); PRTMP (prior temporal); PAST; REDUP (reduplicated); REL (relativizing verb form). The glossing conventions used here are adapted from Gair 2003.
} 


\section{Chris Taylor}

As examples (1) and (2) illustrate, the Sinhala conjunctive participle (which is morphologically marked by the suffix $-(l) l a$ ) performs several of the abovementioned functions characteristic of converbs. For instance, in each example the conjunctive participle expresses temporal sequence, and in (2) we observe narrative chaining, claimed to be characteristic of Asian converbs. Moreover, the verbal form exemplified here does not indicate time reference per se, and as such is less finite than the past tense form which occurs clause-finally.

Despite these similarities between the Sinhala conjunctive participle and Asian converbs, the former may also occur as a nondependent predicate when expressing perfect aspect, which distributionally appears to violate the converbal criteria of nonfiniteness and dependency (Genetti 2005, Hasplemath 1995). This function, which Gair (2003) appropriately describes as "an unusual if not unique feature among South Asian languages," is illustrated by (3) below.

\section{(3) mamə Renu-wə dækka habei dæn æyə gihi-lla \\ I R-ACC see-PAST but now she go-CP \\ I saw Renu but now she has gone.}

While in many respects the Sinhala conjunctive participle functions as a converb (per the definition put forward by Genetti 2005), utterances such as (1)(3) illustrate a type of multifunctionality absent in similar South Asian verbal forms, namely, the functions of both nonfinite clause linking and nondependent predication. Faced with this duality of function, we must decide how best to characterize the relationship between the different uses.

One possibility is to analyze the conjunctive participle form in (1) and (2) as a homonym of the form in (3). Such an account is flawed, however, in that it fails to capture similarities in scene construal among the conjunctive participle's different uses. In contrast, I will argue for a polysemy analysis of the Sinhala conjunctive participle. On this view, certain qualities of the construal traditionally accorded to the expression of perfect aspect are shown to crosscut the interpretations of the two aforementioned grammatical functions, nondependent predication and clause linking. Regarding the latter, I will discuss two specific functions - event sequencing and recapitulation - that provide evidence for analyzing the conjunctive participle as one form with related senses. Specifically, the analysis will demonstrate a parallel between a state's continued relevance to the speech act and the conceptual interrelatedness of certain event sequences.

The paper is structured as follows. After describing the data and methodology used for the study in Section 1, I provide a brief overview of the Sinhala conjunctive participle's functions in Section 2, each of which is subsequently discussed in Sections 2.2-2.5. A summary of the findings relating each of the functions follows in Section 3. 


\section{The Perfect Converb?}

\section{Data and Methodology}

The data used in this study come from three sources, including published literature on Sinhala, structured elicitation, and a small corpus of ten texts. From the latter, which comprises nine narratives and one recipe, only those instances in which the conjunctive participle functions as a clause linker or nondependent predicate were included in the analysis. Such criteria were necessary in order to exclude other uses of the verb form in question which do not fall within the scope of the present study, such as its use in what Genetti (2005) refers to as "conventionalized collocations," as well as the participial form of the verb kiyanno 'tell' kiyala - which functions as a complementizer. In total, 66 target instances of the conjunctive participle were collected from the corpus.

\section{Functions}

\subsection{Overview}

As was illustrated by examples (1) and (2) above, the conjunctive participle expresses the temporal sequence of events, typically in cases of same-subject reference across clauses. This quality of utterances containing the participle is only a tendency, though, in contradistinction with many Indo-Aryan languages (Masica 1991). The utterance in (4) illustrates this point: here, the subject of the first clause, koccis 'train', differs from that of the second, api 'we.'

\section{(4) kocciə æwi-lla api jannə giya train come-CP we go-INF go-PAST}

The train came and we left.

The verb form in question is also often employed successively within an intonation unit to express a sequence of more than two events and/or states (as in example (2)). Such utterances invariably end with a tense-marked verb. In this way, the Sinhala conjunctive participle may be described as a clause chaining strategy (Longacre 1985, Genetti 2005), similar in function to participle or converbal constructions in other languages.

In a similar yet syntactically-distinct function, the conjunctive participle serves to repeat information expressed by an immediately preceding clause. Genetti (2005:49) terms this use of the participle construction in Dolakhae 'recapitulation,' describing it as 'a process common in South Asian narrative, where one begins a syntactic sentence by repeating, often in abbreviated form, the substance of the preceding finite clause or sentence." As (5a)-(5b) below demonstrate, this function of the conjunctive participle is similar to those discussed above, in that the recapitulated event or state is sequenced with a following event or state. 


\section{Chris Taylor}

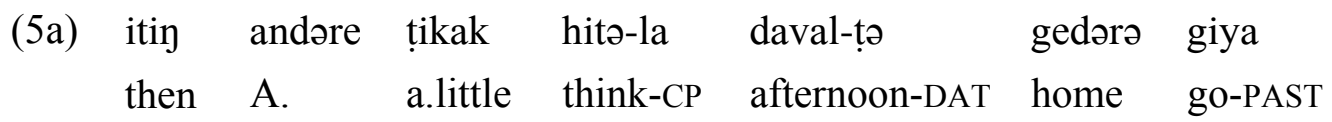

Then Andare pondered for awhile and went home for the afternoon.

(5b)
gedərə gihi-lla eya-ge putaa-ț anḍegaha-lla andəre kiwwa
home go-CP he-GEN son-DAT call-CP A. say-PAST

After going home and calling his son, Andare said...

In (5b), the initial phrase gedoro gihilla '(after) going home' repeats information expressed by the last clause in (7a), namely, that Andare 'went home for the afternoon,' davalto gedoro giya. Moreover, the repeated event is temporally sequenced with two subsequent events: 'calling his son' and a speech event, as we see in (5b). In this way, the conjunctive participle's recapitulative use performs the same sequencing function we see in examples such as (1)-(3).

The last function of the Sinhala participle construction to be examined here is illustrated by example (6) below. In this and similar utterances, the form in question cannot be characterized as dependent, as it occurs either as a monoclausal predicate or as the final verb in a complement clause. The conjunctive participle's use as a nondependent form imposes an aspectual construal of the situation describable in terms of perfect aspect, as indicated by the English translation in (6). Here, the state of having gone, expressed by means of the participle construction, relevantly persists until and bears on the arrival of the speaker's interlocutor in Texas.

$$
\begin{array}{lllllll}
\text { oya } & \text { Texas } & \text { wələțə } & \text { enə-koṭə } & \text { mamə } & \text { Indiawə-țə } & \text { gihi-lla } \\
\text { you } & \text { T. } & \text { PP } & \text { come-PRES-REL-when } & \text { I } & \text { India-DAT } & \text { go-CP }
\end{array}
$$

When you came to Texas I had gone to India.

With the preceding overview in mind, each of these functions is now considered in turn, beginning with event sequencing.

\subsection{Event Sequencing}

As Gair and Paolillo (1997) point out, the conjunctive participle is the most common way of expressing a sequence of actions or events in Sinhala. The corpus data used for the present study indicate that, in the least, such event sequences strongly favor a single agent (or non-patientive) participant which maps onto one noun phrase functioning as the subject of both clauses. In such cases, the two events are highly congruous, sharing a single agentive participant realized as a shared subject relation. This tendency contrasts with the 'participant identity' relationships (i.e. one or two distinct agentive participants) which obtain between events sequenced by other strategies for expressing similar temporal relations. To 


\section{The Perfect Converb?}

this end, at least two other forms are also available, the prior temporal form and the use of an instrumentalized verb immediately followed by the lexeme passe 'after.' The existence of these potential alternatives to the use of the conjunctive participle makes necessary an explanation of one's use over another in a particular context and syntactic environment. Although a comprehensive explanation of this sort is beyond the scope of the present analysis, I present a few preliminary observations below.

First, as was noted above, the expression of an event sequence involving same-subject reference across clauses favors the use of the conjunctive participle. By contrast, nearly all of the utterances taken from the corpus which contain a combination of an instrumentalized verb and passe (5/6 total), as well as half of the utterances containing the prior temporal form (2/4 total), express a sequence of events involving a change in subject. Consider (7) below.

$$
\begin{aligned}
& \text { tikkə welawak giya-in passe toppi welenda nægitta } \\
& \text { a.little time go-INST after hat-PL merchant awaken-PAST }
\end{aligned}
$$

After a little time went by, the hat seller woke up.

The content of the first clause in (7) helps illustrate this form's use in the corpus and elicitation data. Here, the phrase tikko welawak giyain passe 'after a little time went by' renders the temporal relation expressed by the instrumentalized verb-passe combination more transparent. In such cases, the use of this construction as a clause linking strategy entails both nonsimultaneity of the events (or states) and an intervening temporal interval. For example, in (7) a short duration of time passes before the hat seller awakes. This quality of events depicted by the verbal construction in (7) is suggested not only by the translation, 'After X, Y...' but also by elicited minimal pairs varying only in the use of either the conjunctive participle or the combination of an instrumentalized verb and passe, illustrated in (8) and (9) below.

$$
\begin{array}{lllllll}
\text { itin ookə } & \text { dækka-in } & \text { passe } & \text { mage } & \text { yaaluwek } & \text { kiwwa } \\
\text { so that } & \text { see-INST } & \text { after } & \text { I-GEN } & \text { friend } & \text { say-PAST }
\end{array}
$$

So after seeing that, a friend of mine said...

$$
\begin{aligned}
& \text { itin ookə dækə-la passe mage yaaluwek kiwwa } \\
& \text { so that see-CP after I-GEN friend say-PAST }
\end{aligned}
$$

According to the language consultant, the utterance in (8) depicts a situation in which the 'seeing' event concludes a short time before the speaker's friend begins to talk. By contrast, the utterance in (9) can be interpreted as involving temporal overlap, the first event preceding the second inceptively, or, alterna- 


\section{Chris Taylor}

tively, the two events may be interpreted as noncoextensive. Thus, with respect only to temporal sequencing, the instrumentalized verb strategy appears to specify a more fine-grained circumstantial relation between the linked clauses, whereas we observe a coarser depiction of the event sequence temporally in the case of the conjunctive participle.

In this respect, then, the two forms differ in regard to the level of circumstantial specificity afforded by each's use. Moreover, as the corpus data show, the two forms exhibit a degree of complementary specialization with respect to participant identity vis-à-vis the events sequenced; the conjunctive participle being used in same-subject sequences, and the instrumentalized form elsewhere. By contrast, the prior temporal form - which occurs four times in the corpus - does not exhibit a strong tendency for either same or distinct subject sequencing.

Regarding temporal relations and the prior temporal form, however, we do observe a degree of specialization. Consider (10a)-(10b) and (11).

$\begin{array}{lllll}\text { balla } & \text { dangələla-dangələla } & \text { janee-len } & \text { eliyə-ț } & \text { pænna } \\ \operatorname{dog} & \text { fidget-REDUP } & \text { window-from } & \text { out-DAT } & \text { jump-PAST }\end{array}$

The dog kept fidgeting about, and jumped out of the window...

(10b) wætunaamə botəle bin̆di-la laməya balla-wə beerəgattə fall-PRTMP bottle break-CP child dog-ACC rescue-PAST as (he) fell, the bottle broke and the child rescued the dog.

$$
\begin{array}{llllll}
\text { andəree-ţə } & \text { meekə } & \text { æhunamə } & \begin{array}{l}
\text { andəre } \\
\mathrm{e}
\end{array} & & \\
\text { A.-DAT } & \text { this } & \text { hear-PRTMP } & \text { A. } & \text { say-PAST } & \text { king-DAT }
\end{array}
$$

When Andare heard this, he said to the king...

The events in (10b) and (11) either overlap (as in case of the former) or nearly overlap (as in the latter). For instance, in (10b), the termination of the falling event and the bottle's breaking coincide. In (11), a short period of time separates the two events depicted by the utterance. Thus, the prior temporal form contrasts with the instrumentalized verb-passe combination, in that they express different temporal relations. The two forms are similar, however, as they both specify a circumstantial relation, in contrast with the conjunctive participle, whose use expresses only the gross temporal relation of sequence. In this way, the participle form contrasts with both the instrumentalized verb and prior temporal form, which express a more specific temporal relation.

In addition to the differences between the conjunctive participle and the two temporal alternatives discussed above, the data indicate that the former and latter contrast conceptually in the construal imposed by their use on the relation be- 


\section{The Perfect Converb?}

tween the two sequenced events. To illustrate this dissimilarity, first consider (12a)-(12c) below.

(12a) wandura kehelgediya kææwa-in passe mæruna monkey banana eat-INST after die-PAST

After the monkey ate a banana he died.

(12b) wandura kehelgediya kææwaamə mæruna

monkey banana eat-PRTMP die-PAST

When the monkey ate a banana he died.

(12c) wandura kehelgediya kaa-la mæruna

monkey banana eat-CP die-PAST

The monkey ate a banana and died.

In (12a), the combination of instrumentalized verb and passe expresses the nonoverlapping temporal relation between the two events, namely, the monkey eating a banana and the event of its death. Similarly, the utterance in (12b) depicts a specific temporal relation, namely one of near-simultaneity, with the first event minimally-preceding the second. Moreover, in (12c), the use of the conjunctive participle also expresses a temporal relation between the events depicted by each clause, but in this case, the relation is less fleshed-out, indicating only consecution. In this way, the three forms appear to be similar in function, differing only minimally with respect to the nature and degree of the temporal relation specified by each. Furthermore, a correlational interpretation of the event sequence in each utterance above is possible; that is, one may infer a relation between the two events beyond that of temporality. The possibility of such an interpretation of each utterance raises a descriptive question, namely, whether such a construal of the events results from the conventional interpretation evoked by each verb form or is arrived at primarily through an interaction of world knowledge and discourse context. One source of possible explanation comes from elicited utterances, such as (13a)-(13b).

(13a) kurula sindukiwwa-in passe mage amma aawa bird sing-PAST-INST after I-GEN mother come-PAST

After the bird sang, my mother arrived.

(13b) kurula sindukiwwaam ə mage amma aawa bird sing-PRTMP I-GEN mother come-PAST

When the bird sang, my mother arrived. 


\section{Chris Taylor}

Each of these examples depicts a situation involving two events occurring in succession. However, given our knowledge of bird songs and the coming and going of people, the two events are not interpreted as standing in a correlational relation, only one of temporal sequence. Thus, the two verb forms in (13a) and (13b) do not appear to encode a correlation between events beyond that of temporality. With this in mind, we would expect that if the conjunctive participle encoded only temporal consecution, it could felicitously substitute for either verb form in the examples above. This, however, is not the case, as the language consultant rejected the participle's replacement of either the instrumentalized verb or prior temporal form in this and similar utterances, as is illustrated in (13c).

(13c) kurula sindukiyə-la passe mage amma aawa bird sing-CP after I-GEN mother come-PAST

* The bird sang and my mother arrived.

This disparity in usage provides evidence that the Sinhala conjunctive participle does conventionally express a correlational relation between the two events in addition to a relation of temporal sequence.

One potential counterargument to such a proposal relies on distributional evidence, namely, the fact that the conjunctive participle overwhelmingly favors event sequences involving same-subject reference. However, as was discussed in Section 2.1, the participle construction can depict event sequences with distinct subjects, as illustrated by example (4), repeated here as (14).

kocciə æwi-lla api jannə giya
train come-CP we go-INF
go-PAST
The train came and we left.

The train came and we left.

The significance of such utterances lies in the nature of the relation between the two events. In (14), they are not only sequenced, but also exhibit a correlation beyond that of succession. This sequentially-interrelated relevance of events is not evidenced by utterances such as (13a) and (13b) above. Instead, in these and similar utterances, the events are construed as standing only in a temporal relation.

\subsection{Clause Chaining}

In a related function, the conjunctive participle can occur several times in one utterance expressing a sequence of events. This capacity to form clause chains (Genetti 2005, Longacre 1985, Myhill and Hibiya 1988) is illustrated by (15). 
She woke up, made coffee, read the paper and left.

In this utterance, we observe a series of events, temporally-sequenced, involving one subject shared by each clause. Moreover, the sequence of events exhibits a type of correlational coherence absent in utterances such as (13a)-(13b) above. For instance, the events in (15) taken together constitute a larger 'macro-event,' namely, what may be termed a prework morning ritual. Each clause thus describes one subevent, the completion of which brings the utterance's subject one step closer to the culmination of the event chain: departure for work. In this way, the completion of each act — waking up, making coffee, and reading the paper-bears relevantly on the subsequent event in the chain.

Thus, the two preceding functions of the conjunctive participle-(simple) event sequencing and clause chaining - correspond conceptually in their construal of event sequences. Specifically, as demonstrated by the discussion of examples illustrative of both functions, the state resulting from an anterior action, such as making the coffee, exhibits a continued relevance bearing on the inception of a subsequent event. In this way, each use of the conjunctive participle expresses both a correlational relation between events and a coarse temporal relation.

\subsection{Recapitulation}

In addition to the preceding functions, the conjunctive participle is also used in cases of recapitulation, as described in Section 2.1. In this capacity, the form in question not only performs the discourse function of repetition, but also serves to sequence two events: one expressed by the repeated information and another predicated by a following clause. Furthermore, the observed correlational relation between successive events is also in evidence, as illustrated by (16a)-(16b).

(16a) baisikəle galəkə hæpuna

bicycle stone hit-PAST

The bicycle hit a stone.
galəkə hæpi-la laməya-i persgedi okomə bimə wæțuna stone hit-CP child-CONJ pears all ground fall-PAST
After hitting the stone, the child and the pears all fell to the ground.

In this case, as a result of the first event, the boy riding the bicycle loses his balance and consequently falls to the ground. Thus, the state of imbalance relevantly bears on the boy's fall. 


\section{Chris Taylor}

\subsection{Non-Dependent Predication}

As was noted in the Introduction, the Sinhala conjunctive participle is unique among Indo-Aryan languages in its capacity to function as a nondependent predicate. Moreover, in such cases, the participle expresses perfect aspect, as illustrated by the following example.

$$
\begin{array}{llllll}
\text { oya heț } & \text { enə-koțə } & \text { mamə } & \text { California } & \text { wələțə gihi-1la } \\
\text { YOU tomorrow } & \text { come-PRES-REL-when } & \text { I } & \text { C. } & \text { PP } & \text { go-CP }
\end{array}
$$

When you come tomorrow, I will have left for California.

Following Comrie (1976:52), I take perfect aspect to indicate "the continuing... relevance of a past situation." We observe this sense precisely in (23) above, in which the continued relevance of 'having left' persists until the interlocutor's expected arrival. Similarly, in (18a)-(18b), we see that the resulting state of the theft relevantly bears on the man's observation that his food has been taken, depicted by the participial form of the verb kəranno 'do' in the expression horəkam kərəla.

(18a) ohuge baharyawə hoyənə-gaman

he-GEN wife look-PRES-REL-when

While looking for his wife...

(18b) horek tamange kææmə horəkam kərə-la kiyəla ohu dææka robber self-GEN food theft do-CP COMP he see-PAST he saw that a robber had stolen his food.

As examples (17) and (18a)-(18b) show, the Sinhala conjunctive participle can function as a nondependent predicate, occurring as either the main clause verb or embedded in a complement clause. In such cases, we observe a meaning consistent with the interpretation traditionally attributed to the expression of perfect aspect.

\section{Common Construal}

To summarize the findings relating each function considered above (event sequencing, clause chaining, recapitulation, and nondependent predication), we observed first, in cases of two-event sequences, that the conjunctive participle expresses a correlation between the events in addition to a rough temporal relation, as we see in example (19) below. 


\section{The Perfect Converb?}

$\begin{array}{llllllll}\text { may } & \text { gihi-lla } & \text { ee } & \text { kaaryaləyin } & \text { æhua } & \text { mage } & \text { bææg } & \text { ekə } \\ \text { I } & \text { go-CP } & \text { that } & \text { office } & \text { ask-PAST } & \text { I-GEN } & \text { bag } & \text { one }\end{array}$

\section{kohedə kiyəla}

where COMP

I went to that office and asked 'Where is my bag?'

Here, the conjunctive participle not only sequences the events of going and asking, but also profiles the correlational coherence between the two events. This correlation, which was shown to be in evidence for the related functions of clause chaining and recapitulation, involves the continued relevance of a resultant state bearing on the event expressed by the following clause. In example (19) above, the resultant state of the speaker going to 'that office' relevantly bears on the inquiry made once there. This relationship among events has been observed in Dravidian and Indo-Aryan languages by Lindholm (1975) and Masica (1991:400), respectively, the latter noting that, in regard to the conjunctive participle's use as a clause linkage strategy, "not just any two clauses may be so linked: they must have what [Lindholm] calls 'natural relevance' - an elusive concept when one tries to define it, but independently cited by other investigators."

With respect to the construal imposed by the conjunctive participle's use as a nondependent predicate, we observe a similar relationship in the expression of perfect aspect. In such cases, the participle expresses the continued relevance of a resultant state to the speech act, as well as the moment of a past or future event, as illustrated in (20) below.

$$
\begin{array}{llllll}
\text { gəhæni } & \text { kukula-wə } & \text { marə-la } & \text { dæn } & \text { hæmotəmə kaanə } & \text { puluwan } \\
\text { woman } & \text { chicken-ACC } & \text { kill-CP } & \text { now } & \text { everyone } & \text { eat- INF }
\end{array}
$$

The woman has killed the chicken and now everyone can eat

In this example, the resultant state of the first event, namely that of killing a chicken, relevantly bears on the speaker's immediate situation at the time of the utterance. Specifically, the state expressed by the second clause follows as a consequence of killing the chicken. Thus, the construal evoked by the participle's use in utterances such as (20) parallels the construal imposed by its use as a clause linkage strategy, exemplified in (19). In both cases, a correlational coherence obtains between two situations which involves the resultant state of a prior event relevantly persisting until and directly bearing on a succeeding event. In this way, the scene construal characteristic of perfect aspect conceptually unites the syntactically-disparate functions. 


\section{Chris Taylor}

\section{Conclusion}

The significance of the findings presented here are twofold. First, I have presented evidence in favor of a polysemy analysis of the Sinhala conjunctive participle. Specifically, I have argued that a 'common construal' is in evidence for each of the participle's distinct syntactic functions. This construal, which involves a correlational relationship between a prior event and a subsequent situation, crosscuts each of the conjunctive participle's functions discussed above. Second, I have shown that the form in question performs a number of the functions typical of converbal constructions, despite its capability to serve as a nondependent predicate. These observations contribute to the ongoing typological dialogue concerned with establishing a crosslinguistic characterization of such forms.

\section{References}

Bickel, Balthasar. 1998. Review of Converbs in Cross-Linguistic Perspective, by Martin Haspelmath and Ekkehard König, eds. Linguistic Typology 2:381-397.

Gair, James W. 1970. Colloquial Sinhalese Clause Structures. The Hague: Mouton.

Gair, James W. 1976. The verb in Sinhala, with some preliminary remarks on Dravidianization. International Journal of Dravidian Linguistics 5(2):259273.

Gair, James W. 2003. Sinhala. In G Cardona and D. Jain, eds., The Indo-Aryan Languages, 766-817. London: Routledge.

Gair, James W. and John Paolillo. 1997. Sinhala. München: LINCOM Europa.

Genetti, Carol. 2005. The Participle Construction of Dolokha Newar: Syntactic Implications of an Asian Converb. Studies in Language. 29(1):35-87.

Haspelmath, Martin. 1995. The Converb as a Cross-Linguistically Valid Category. In M. Haspelmath and E. König, eds., Converbs in Cross-Linguistic Perspective, 1-55. Berlin: Mouton de Gruyter.

Hasplemath, Martin and Ekkehard König. 1995. Converbs in Cross-Linguistic Perspective. Berlin: Mouton de Gruyter.

Lindholm, James. 1975. The Conceptual Basis of the Tamil Adverbial Participle. Ph.D. diss., University of Chicago.

Longacre, Robert. 1985. Sentences as combinations of clauses. In T. Shopen, ed., Language Typology and Syntactic Description 2: Complex Constructions, 235-286. Cambridge: Cambridge University Press.

Masica, Colin. 1976. Defining a Linguistic Area. Chicago: University of Chicago Press.

Masica, Colin. 1991. The Indo-Aryan Languages. Cambridge: Cambridge University Press.

Myhill, John and Junko Hibiya. 1988. The Discourse Function of Clause Chaining. In J. Haiman and S. Thompson, eds., Clause Combining in Grammar and Discourse, 361-398. Amsterdam: John Benjamins. 
The Perfect Converb?

Chris Taylor

Rice University

Dept. of Linguistics, MS 23

6100 Main St.

Houston, TX 77005-1892

sastre@rice.edu 